Finisterra, XXXVI, 71, 2001, pp. 61-82

\title{
AS CHEIAS NO SUL DE PORTUGAL EM DIFERENTES TIPOS DE BACIAS HIDROGRÁFICAS
}

\author{
Catarina Ramos ${ }^{1}$ \\ EUSÉBIO REIS ${ }^{2}$
}

\begin{abstract}
Resumo - No século XX, as cheias foram o desastre natural mais mortífero em Portugal, seguidas pelos sismos: por cada morte devida aos sismos morreram sete pessoas devido às cheias.

O tipo de cheias conhecidas como «cheias progressivas» afectam principalmente as grandes bacias hidrográficas, como a do rio Tejo, provocando a inundação de uma ampla área. Este tipo de cheias é causado por períodos de chuva abundante relacionada com a circulação zonal de oeste que se mantém durante semanas. O sistema de barragens da bacia reduz a frequência das cheias mas não consegue «domar» o rio, contribuindo mesmo, por vezes, para o aumento do pico de escoamento, tal como aconteceu em 1979. Apesar disso, estas cheias não constituem, geralmente, um perigo para a população. As cheias rápidas, pelo contrário, são perigosas e mortíferas, tais como as que ocorreram em 1967, 1983 e 1997. Afectam as pequenas bacias de drenagem e são causadas por chuvadas fortes e concentradas, devido a depressões convectivas (gotas frias extremamente activas ou depressões estacionárias causadas pela interacção entre as circulações polar e tropical), nomeadamente no Sul do País (região de Lisboa, Alentejo e Algarve). A desflorestação, a impermeabilização dos solos, a urbanização caótica, a construção em leitos de cheia, o entulhamento dos pequenos cursos de água, ou a sua canalização, a construção de muros e aterros transversais ao sentido de escoamento das linhas de água, que funcionam como diques, contribuem para a agravamento deste tipo de cheias.

São aqui analisadas as cheias nos rios do Sul do País, desde as grandes bacias de drenagem (rio Tejo, $80100 \mathrm{~km}^{2}$ ) até às mais pequenas (ribeira de Cobres, $700 \mathrm{~km}^{2}$; ribeira da Garganta, $1 \mathrm{~km}^{2}$ ).
\end{abstract}

Palavras-chave: regime fluvial, bacias de drenagem, tipos de cheias, barragens.

Abstract - THE FLOODS IN THE SOUTH OF PORTUGAL IN DIFFERENT KINDS OF DRAINAGE BASINS - The regime of the Portuguese rivers depends on the space and time variation of rainfall. Portugal has clear regional contrasts in the geographical distribution of rainfall. The NW and the Central Mountain Range (Cordilheira Central) are the regions with more rainfall. The $\mathrm{NE}$ and the south are the driest regions. The rainfall regime is very irregular. The monthly rainfall regime is clearly Mediterranean with autumn-winter rains (November-March) and an extremely dry summer.

\footnotetext{
1 Investigadora do Centro de Estudos Geográficos, Prof. ${ }^{a}$ Auxiliar da Universidade de Lisboa. Email: ceg@mail.telepac.pt.

2 Investigador do Centro de Estudos Geográficos, Assistente da Universidade de Lisboa. Email: ejmreis@mail.telepac.pt.
} 
The river flows are also very irregular, with severe droughts and surprisingly high flood discharges. These characteristics tend to worsen from NW to SE. The southern rivers have specific discharges 6 to 7 times inferior to the ones of the NW, greater irregularity (the flow in years with more rainfall may surpass 100 to 240 times the flow in driest years), a more severe drought (6 months), almost all are temporary, and flood peaks (200-300 times the average flow) can reach extremely high values.

In the twentieth century, floods were responsible for the highest rate of casualties in natural disasters in Portugal, followed by earthquakes: one death for every seven were due to floods.

The type of floods known as «progressive floods» mainly affects the big hydrographic basins, such as the River Tagus basin, due to the large flooded area. This kind of flood is caused by heavy rainfall periods connected to the western zonal circulation, which usually lasts several weeks. The dams' basin system reduces flood frequency, especially in autumn when reservoirs still manage to absorb the high flows after the summer dry period, but cannot «tame» the river. It has even contributed to an increase of the peak flow, as in the 1979 flood. Flashfloods are another kind of floods that occur in Portugal and, unlike the former, are dangerous and deadly, such as those in 1967, 1983 and 1997. They affect the small drainage basins and are caused by heavy and concentrated rainfalls, due to convective depressions (cold pools especially active or depressions caused by the interaction between polar and tropical circulations), namely in the south of the country (Lisbon region, Alentejo and Algarve). In the small drainage basins with a natural regime (uninfluenced by a dam), it is interesting to verify the existence of a trend in these extreme phenomena over the last decades. There has been a clear intensification of flood importance during autumn months, in contrast with an accentuated diminishing in winter and spring months.

This trend concerns us mainly for two reasons. Firstly, the rainfall concentration in fewer months lessens its availability in the other months and requires a greater storage capacity. Secondly, this concentration means a bigger rainfall intensity in autumn, with the worsening of the number and intensity of floods and a greater soil loss. Deforestation, soil impermeability, chaotic urbanisation, building on floodplains, the blocking up of small creeks, or their canalisation, the building of walls and transverse embankments along the small creeks courses that work as dikes, contribute to the aggravation of this kind of floods.

The floods in rivers of southern Portugal are here analysed, and range from the big drainage basins (River Tagus, $80100 \mathrm{~km}^{2}$ ), to the smaller ones (Cobres stream, $700 \mathrm{~km}^{2}$; Garganta stream, $1 \mathrm{~km}^{2}$ ). Also discussed are the human causes that have contributed to increasing the consequences of the floods in small catchments.

Key words: fluvial regime, drainage basins, catchments, flood types, dams.

\section{INTRODUÇÃO}

O regime dos rios portugueses depende essencialmente da variação temporal da precipitação e acompanha de perto os contrastes regionais na distribuição geográfica das chuvas. O Noroeste e a Cordilheira Central, que divide o Norte do Sul do País, são as regiões com maiores valores de precipitação (1200 - $3000 \mathrm{~mm} / \mathrm{ano})$, pois, além de serem as mais montanhosas, são 
frequentemente atravessadas por superfícies frontais ligadas a depressões subpolares. O Nordeste e o Sul são as regiões mais secas (400-900 mm/ano): o Nordeste, porque se encontra em situação de abrigo, rodeado por barreiras montanhosas; o Sul, porque é afectado, com maior frequência pelas altas pressões subtropicais (Anticiclone dos Açores).

O regime da precipitação, tanto em termos interanuais como intermensais, é bastante irregular. O ritmo mensal da precipitação é claramente mediterrâneo com chuvas no Outono e Inverno (Novembro a Março) e com um Verão extremamente seco.

O comportamento dos rios é também muito irregular, com uma estiagem prolongada e com caudais de cheia que atingem valores surpreendentes. Estas características tendem a acentuar-se de noroeste para sudeste (Quadro I). Os rios do Sul possuem escoamentos específicos anuais 6 a 7 vezes inferiores aos do Noroeste, uma maior irregularidade (o caudal nos anos mais chuvosos pode ultrapassar 100 a 240 vezes o dos anos mais secos), uma estiagem mais prolongada (6 meses), sendo quase todos temporários, e com pontas de cheia que atingem valores exorbitantes (200 a 300 vezes o caudal médio anual; RAmos, 1994 e 1996a).

Cerca de $80 \%$ do país possui um substrato geológico com permeabilidade reduzida (granitos, xistos e formações argilosas). Apenas os rios com nascentes alimentadas pelos calcários carsificados do Centro do País (Quadro I) apresentam uma evidente ponderação, que contribui para diminuir a irregularidade e os picos de cheia (RAMOs, 1993, 1994 e 1996b).

QuADRO I - O regime dos rios portugueses

TABLE I-Portuguese rivers regime

\begin{tabular}{|l|c|c|c|c|}
\hline \multicolumn{1}{|c|}{ Rios } & $\begin{array}{c}\text { Caudal específico } \\
\left(\mathbf{l} / \mathbf{s} / \mathbf{k m}^{\mathbf{2}}\right)\end{array}$ & $\begin{array}{c}\text { Irregularidade } \\
(\mathbf{Q m a x} / \mathbf{Q m i n})\end{array}$ & $\begin{array}{c}\text { Estiagem (meses } \\
\mathbf{5 2 5 \%} \mathbf{~ d e} \mathbf{Q})\end{array}$ & $\begin{array}{c}\text { Cheias } \\
(\mathbf{Q m i} / \mathbf{Q})\end{array}$ \\
\hline $\begin{array}{l}\text { Noroeste e } \\
\text { Cordilheira Central }\end{array}$ & $20-35$ & $6-9$ & 3 & $50-60$ \\
\hline Nordeste & $6-12$ & $10-40$ & 4 & $60-90$ \\
\hline Sul & $3-5$ & $100-240$ & 6 & $200-300$ \\
\hline Áreas cársicas centrais & $15-40$ & $4-5$ & $3-5$ & $25-40$ \\
\hline
\end{tabular}

Q - caudal médio anual; Qmi - caudal máximo instantâneo; Qmax e Qmin - Caudais dos anos, respectivamente, com maior e com menor escoamento.

(Séries temporais de 1960/61 a 1989/90 e áreas de drenagem $>300 \mathrm{~km}^{2}$, excepto as séries das áreas cársicas 1980/81 a 1989/90 e áreas de drenagem $>100 \mathrm{~km}^{2}$ ) 


\section{TIPOS DE CHEIAS E CAUSAS METEOROLÓGICAS}

As cheias progressivas são causadas por longos períodos chuvosos que podem durar semanas, relacionados com a permanência da circulação zonal de oeste. Neste tipo de circulação, a Península Ibérica é varrida por chuvas frontais, provocadas pela passagem sucessiva de depressões sub-polares e sistemas frontais a elas associados. Estas depressões, que circulam normalmente à latitude das Ilhas Britânicas, encontram-se, neste caso, a latitudes muito baixas (entre $40^{\circ}$ e $45^{\circ} \mathrm{N}$ ).

As cheias rápidas devem-se a curtos períodos chuvosos, mas de grande intensidade, relacionados fundamentalmente com depressões convectivas (FERREIRA, 1985): gotas de ar frio particularmente activas ou depressões resultantes da interacção das circulações polar e tropical.

As gotas de ar frio são muito frequentes em Portugal Continental. Estas depressões resultam de invasões de ar frio (polar ou árctico) em altitude, que se estendem até latitudes subtropicais (entre $40^{\circ}$ e $30^{\circ} \mathrm{N}$ ). Elas são mais frequentes na área compreendida entre o SW da Península Ibérica, a ilha da Madeira e o arquipélago dos Açores, afectando assim particularmente a região Sul do país. As chuvas de maior intensidade ocorrem quando existe um forte gradiente vertical da temperatura entre a advecção fria em altitude e o ar quente e húmido da baixa troposfera, que fornece o vapor de água necessário às condensações abundantes (VENTURA, 1987). A temperatura das águas oceânicas é assim importante. O Outono é a época do ano mais problemática não só porque o oceano tem uma maior quantidade de calor armazenada, mas também porque o enfraquecimento do anticiclone dos Açores e a intensificação da cir-culação meridiana favorece a individualização das gotas frias.

As depressões convectivas que resultam da interacção da circulação polar e tropical têm um máximo de frequência de ocorrência em Novembro, embora com uma grande variabilidade interanual. «O seu aparecimento depende não somente da intensidade convectiva da C.I.T. (Convergência Intertropical), mas também da sua interligação com as invasões de ar frio suficientemente grandes para atingir as latitudes subtropicais» (FERREIRA, 1985, p.33).

\section{AS CHEIAS NUMA GRANDE BACIA HIDROGRÁFICA (RIO TEJO)}

\section{O comportamento hidrológico do rio Tejo}

O rio Tejo é o mais comprido da Península Ibérica, com cerca de $1.100 \mathrm{~km}$. A sua bacia hidrográfica está entre as 20 maiores da Europa, com $80.100 \mathrm{~km}^{2}$, 2/3 das quais em Espanha e 1/3 em Portugal (Fig. 1a).

O caudal médio anual estimado no estuário é $444 \mathrm{~m}^{3} / \mathrm{s}$ (DAVEAU, 1995), o que faz dele o segundo rio com maior caudal em Portugal. O Tejo é um rio relativamente irregular (cerca de duas vezes mais que o rio Douro, mas cerca de três vezes menos que o rio Guadiana): a relação entre os anos extremos foi 
$17\left(650 \mathrm{~m}^{3} / \mathrm{s}\right.$ e $37 \mathrm{~m}^{3} / \mathrm{s}$, num período de 30 anos de medições em V. V. Rodão, Quadro II). Possui um regime pluvial em Portugal, do tipo subtropical, com 3 meses de escoamento elevado (Dezembro a Fevereiro) e um pico anual, em Fevereiro, o qual atinge 2,5 vezes o caudal médio anual.

Quadro II - Comportamento hidrológico dos rios Douro, Tejo e Guadiana

Table II - Hydrological behaviour of the Rivers Douro, Tagus and Guadiana

\begin{tabular}{|c|c|c|c|c|c|}
\hline \multirow{2}{*}{ Rios } & \multirow{2}{*}{$\begin{array}{c}\text { Área da } \\
\text { Bacia }\left(\mathrm{km}^{2}\right)\end{array}$} & \multicolumn{2}{|c|}{ Caudais estimados na foz } & \multirow{2}{*}{$\begin{array}{l}\text { Irregularidade } \\
\text { (Qmax/Qmin) }\end{array}$} & \multirow{2}{*}{$\begin{array}{l}\text { Maior cheia conhecida } \\
\text { (Qp) }\end{array}$} \\
\hline & & $\begin{array}{l}\text { Médio } \\
\left(\mathrm{m}^{3} / \mathbf{s}\right)\end{array}$ & $\begin{array}{c}\text { Específico } \\
\left(\mathbf{l} / \mathbf{s} / \mathbf{k m}^{2}\right)\end{array}$ & & \\
\hline Douro & 98400 & $\begin{array}{c}704 \\
\text { (Porto) }\end{array}$ & 7,1 & $\begin{array}{c}9 \\
\text { (Régua) }\end{array}$ & $\begin{array}{c}\text { Dezembro de } 1739 \\
\text { (avaliado em } 19.000 \mathrm{~m}^{3} / \mathrm{s} \text { no } \\
\text { Porto; S. Daveau, 1995) }\end{array}$ \\
\hline Tejo & 80100 & $\begin{array}{c}444 \\
\text { (Lisboa) }\end{array}$ & 5,5 & $\begin{array}{c}17 \\
\text { (V. V. Rodão) }\end{array}$ & $\begin{array}{c}\text { Fevereiro de } 1979 \\
\left(14.500 \mathrm{~m}^{3} / \mathrm{s} \text { em Santarém }\right)\end{array}$ \\
\hline $\begin{array}{l}\text { Gua- } \\
\text { diana }\end{array}$ & 66900 & $\begin{array}{c}178 \\
\text { (V. R. } \\
\text { S }^{\text {to }} \text { António) }\end{array}$ & 2,7 & $\begin{array}{c}54 \\
(\text { Pulo do Lobo })^{3}\end{array}$ & $\begin{array}{c}\text { Março de } 1947 \\
\left(8.000 \mathrm{~m}^{3} / \mathrm{s} \text { no Pulo do Lobo }\right)\end{array}$ \\
\hline
\end{tabular}

(Q - caudal médio anual; Qmax/Qmin - ano mais húmido/ano mais seco; Qp - caudal de ponta (Q - annual mean discharge; Qmax/Qmin - rainiest year/driest year; Qp - peak discharge)

Em Portugal, o vale do Tejo está dividido em dois sectores distintos. No sector montante, no Maciço Antigo, o rio escoa de ENE para WSW, até um pouco a jusante da estação hidrométrica de Almourol (Fig.1a). Neste troço, bastante encaixado, o vale estreita quando cruza as cristas quartzíticas ou granitos mais resistentes, e as cheias podem atingir alturas impressionantes: na maior cheia, desde que há registos, as águas subiram mais de 25 metros em Vila Velha de Rodão. A jusante de Almourol, o rio entra na extensa Bacia Sedimentar Cenozóica, e o vale alarga-se consideravelmente, sendo o sentido de escoamento de NE para SW até Lisboa. Esta secção corresponde ao baixo vale do rio Tejo e é aqui que ocorrem as cheias mais espectaculares do território português, devido à extensão da área inundada (mais de $800 \mathrm{~km}^{2}$, Fig.1a). A planície aluvial permanece completamente submersa durante as grandes cheias do Tejo: a partir de 7 metros de altura hidrométrica as águas espraiam-se, alagando-a, mas não ultrapassam os 9 metros, mesmo durante as maiores cheias.

\footnotetext{
3 Nos últimos 20 anos, a construção de várias barragens em Espanha, para fornecimento de água a extensas áreas irrigadas, levou à diminuição do caudal do rio para menos de metade, agravando assim a sua estiagem e irregularidade (Qmáx./Qmín.>77).
} 
66

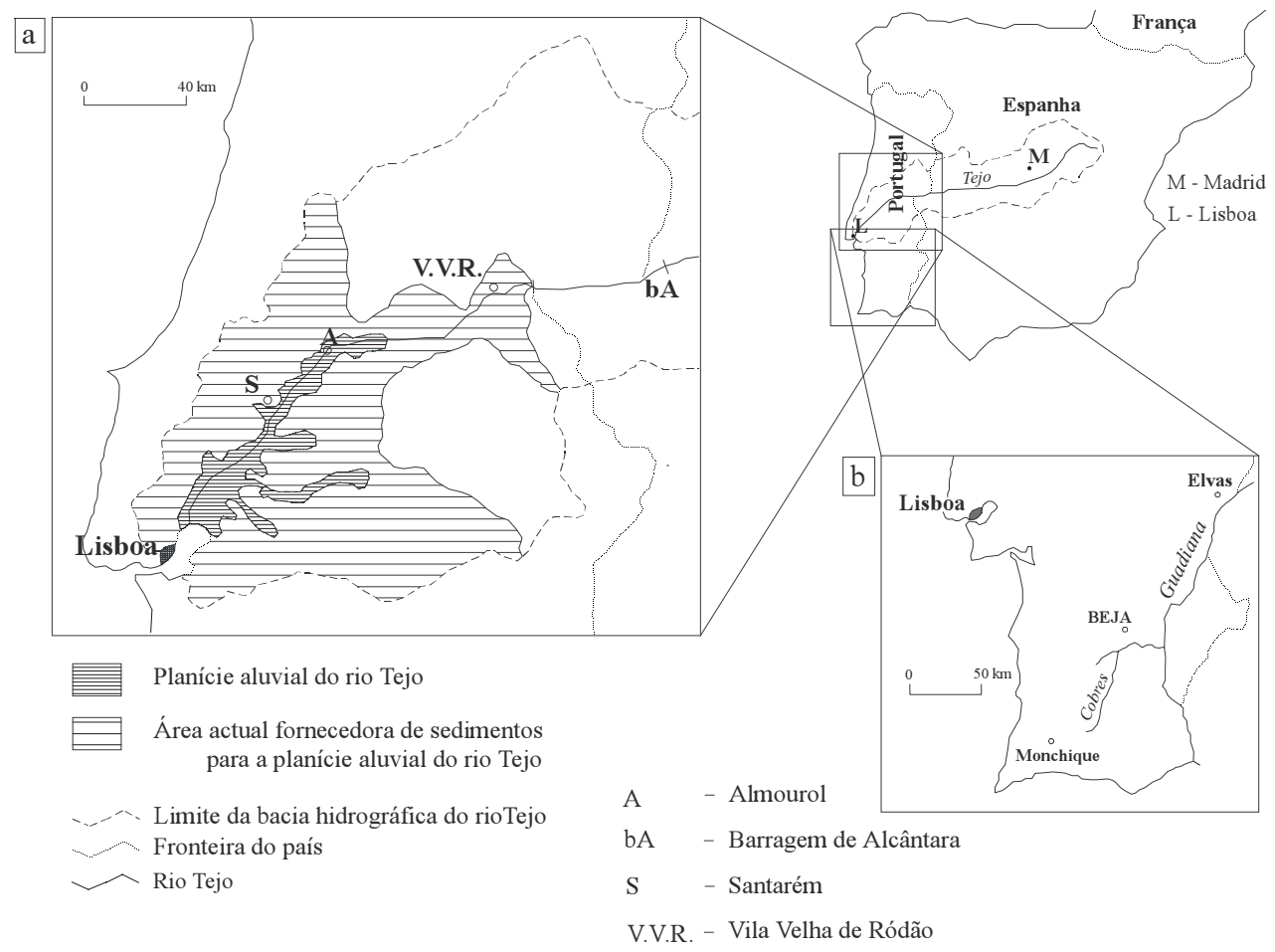

FIg. 1 - Localização das bacias hidrográficas estudadas: a) rio Tejo; b) ribeiras de Cobres e de Garganta

FIG. 1 - Location of the studied drainage basins: a) River Tagus; b) Cobres stream and Garganta stream

O alastramento das águas através desta vasta planície de inundação protege Lisboa das cheias do Tejo, visto que, junto a esta cidade, a subida do nível do rio não excede os 0,5 metros nas maiores cheias (DAVEAU, 1987).

Quando atinge a altura hidrométrica de 6,4 m em Santarém, o rio Tejo inicia o transbordo. Tomando este valor como referência, no período entre 1945 e 1970, registaram-se 50 cheias no baixo vale do Tejo (ou seja, com uma frequência média de 2 vezes/ano). De Janeiro a Março ocorreram $70 \%$ das cheias (DGRAH, 1979 ).

A maior cheia registada ocorreu em Fevereiro de 1979 (Quadro II), alcançando o caudal de ponta $14.500 \mathrm{~m}^{3} / \mathrm{s} \mathrm{em} \mathrm{Santarém}(8,89 \mathrm{~m}$ de altura), ou seja, 36 vezes o caudal médio do rio $\left(405 \mathrm{~m}^{3} / \mathrm{s}\right.$ em Santarém), 72 vezes o caudal mediano e 273 vezes o caudal característico de estiagem. O período de retorno foi avaliado em 220 anos através da distribuição de Pearson tipo III (SOBRINHo, 1980). 


\section{O impacto das barragens}

A grande irregularidade do rio e as cheias frequentes levaram à intervenção humana na planície aluvial do rio Tejo, pelo menos desde há 8 séculos (AleXandre e Borralho, 1982). No último século, o rio sofreu uma crescente intervenção humana que modificou o seu comportamento hidrológico através da construção de mais de 140 barragens (em Espanha e em Portugal). O surto da construção de barragens teve lugar nos anos 50 e 60 (Fig.2), em particular no lado espanhol da bacia. Enquanto antes de 1950 a capacidade de armazenamento das barragens espanholas era de $4 \%$ do escoamento médio anual, nos anos 80 era de $76 \%$. Actualmente, a capacidade total de armazenamento das barragens espanholas e portuguesas constitui 95\% do escoamento médio anual do rio (DAVEAU, 1995).

Podem-se estabelecer três períodos no que diz respeito ao crescimento da capacidade das barragens e à artificialização resultante do regime do rio: o $1 .^{\circ}$ período, antes de 1950, que representa o regime natural; o $2 .^{\circ}$ período, entre 1950 e 1970, que representa uma clara artificialização durante o surto da construção de barragens; o $3 .^{\circ}$ período após 1970 , quando o regime do Tejo português passou a depender principalmente da barragem espanhola de Alcântara, localizada perto da fronteira portuguesa (Fig.1), cujo reservatório possui uma capacidade de armazenamento de $1 / 4$ do total da água armazenada em todas as barragens da bacia (DAVEAU, 1995).

O estudo efectuado por LOUREIRo e MACEDo (1986), acerca do impacto das barragens nos caudais do Tejo, usando o método da curva dos caudais médios diários classificados (Quadro III e Fig. 3), mostra claramente que existe uma

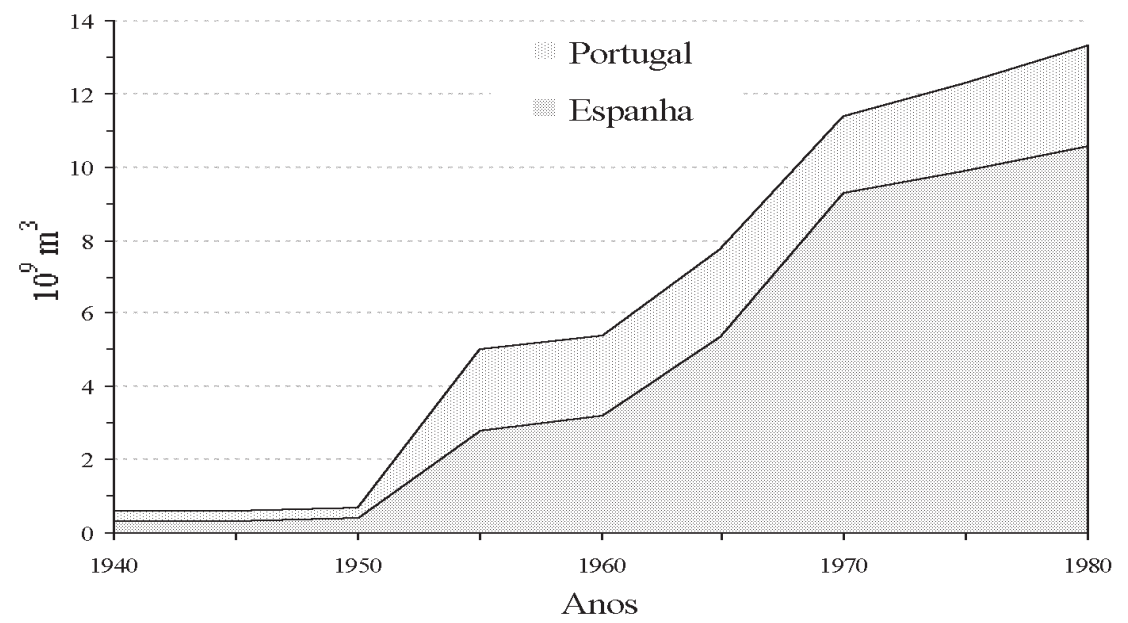

FIg. 2 - Capacidade de armazenamento das barragens na bacia hidrográfica do Tejo FIG. 2 - Dam storage capacity of the River Tagus drainage basin. (S. DAVEAU, 1987) 


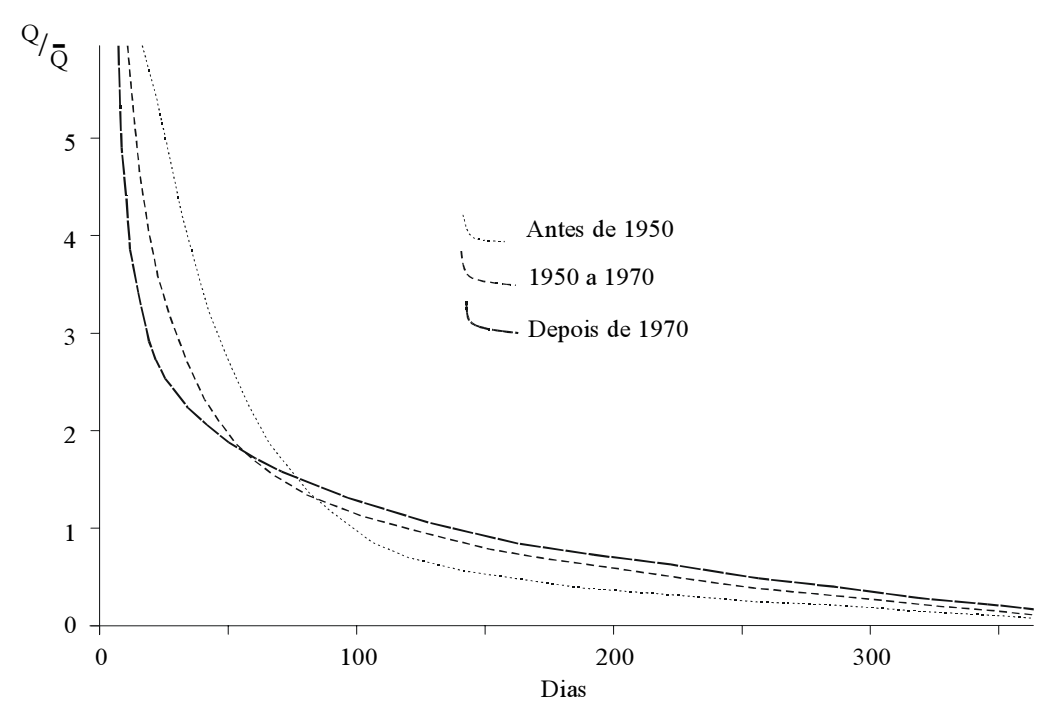

FIG. 3 - O rio Tejo em Santarém: caudais médios diários classificados

FIG. 3 - River Tagus at Santarém: classified daily average discharges. (LOUREIRO E MACEDO, 1986)

tendência para a redução dos caudais mais elevados e da frequência das cheias. Compreensivelmente, este facto é mais notável durante as cheias de Outono do que durante as cheias de Inverno, visto que, após o período seco de Verão, as barragens possuem uma maior capacidade de encaixe do escoamento.

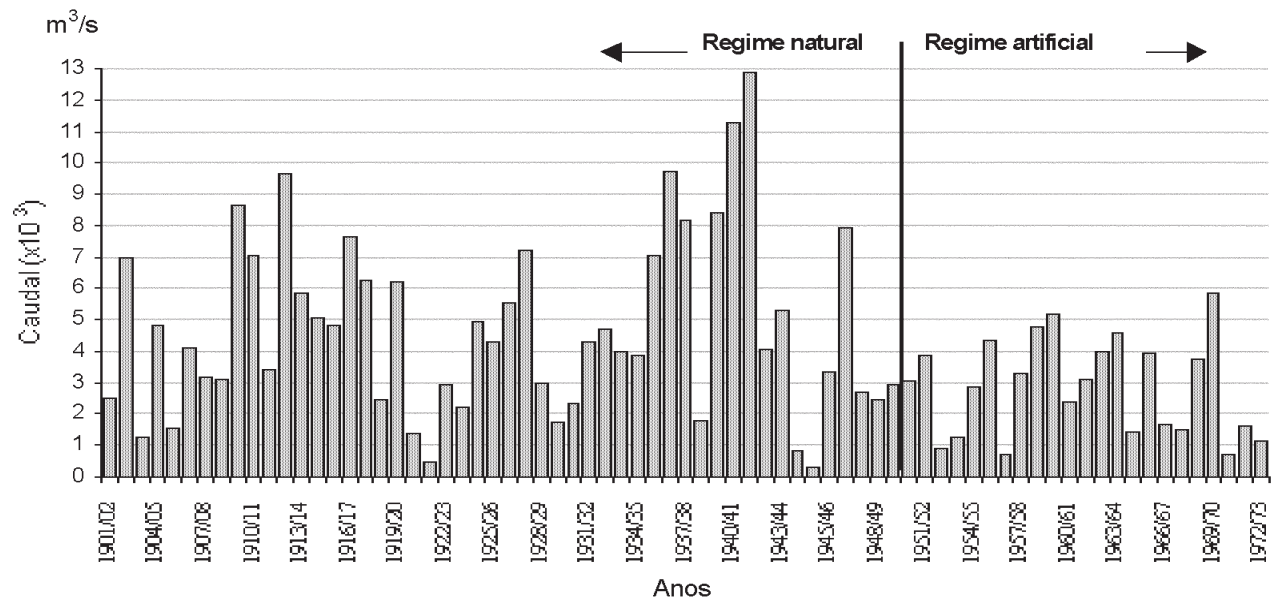

FIg. 4 - Caudal máximo instantâneo em Vila Velha de Ródão (1901/02-1972/73)

FIG. 4 - Instantaneous maximum discharge at Vila Velha de Ródão (1901/02-1972/73)

(Fonte/Source: Instituto da Água) 
Entre o $1 .^{\circ}$ e o $2 .^{\circ}$ período, a amplitude de flutuação dos caudais máximos instantâneos diminuiu cinco vezes (Fig.4) e os caudais máximos instantâneos mais elevados (> $6000 \mathrm{~m}^{3} / \mathrm{s}$ ) desapareceram (Figs. 4 e 5).

Por outro lado, o escoamento durante a estiagem sofre um aumento evidente quando comparado com o observado num regime natural. As estiagens tornam-se, assim, mais curtas e menos pronunciadas ( 3 meses, no $1 .^{\circ}$ período, e apenas 1 mês, no $3 .^{\circ}$ período; Quadro III e Fig. 3).

QUADRO III - O impacto das barragens nos caudais do Tejo

TABLE III - The impact of dams on the Tagus discharges

\begin{tabular}{|c|c|c|c|}
\hline N. $^{\mathbf{0}}$ de dias com um caudal & Antes de $\mathbf{1 9 5 0}$ & $\mathbf{1 9 5 0 - 1 9 7 0}$ & Após 1970 \\
\hline$>3 Q$ & 45 & 27 & 15 \\
\hline$<1 / 5 Q$ & 95 & 45 & 25 \\
\hline
\end{tabular}

Q - caudal médio anual

(LOUREIRO e MACEDO, 1986)

O impacto das barragens é ainda visível nos caudais sólidos medidos no Baixo Tejo, devido não só à diminuição do número de cheias como também à diminuição da área da bacia que para eles contribui (Fig.1). De facto, o trans-

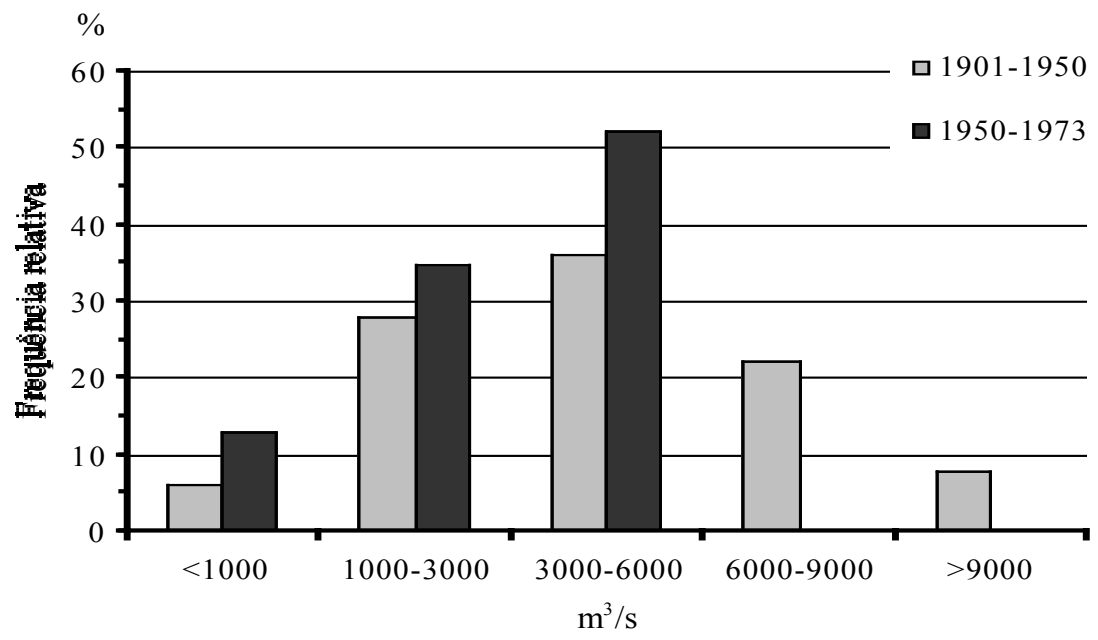

FIG. 5 - Caudais máximos instantâneos classificados em Vila Velha de Ródão (1901/02-1972/73)

FIG. 5 - Classified instantaneous maximum discharge at Vila Velha de Ródão (1901/02-1972/73)

(Fonte/Source: Instituto da Água) 
porte sólido sofreu também um decréscimo acentuado, como se constatou nos estudos de Quintela et al. (1982). Considerando o transporte sólido durante os três períodos mencionados, estes autores chegaram à conclusão que existiu um decréscimo de $71 \%$ (Quadro IV).

A retenção dos sedimentos nas albufeiras, tem como consequência directa uma acentuada erosão das praias situadas a sul do estuário do Tejo, as quais são alimentadas principalmente a partir das areias fluviais.

QuADRo IV - O impacto das barragens no transporte sólido do Tejo TABLE IV-The impact of dams on the Tagus bedload transport

\begin{tabular}{|c|c|c|}
\hline Antes de 1950 & $\mathbf{1 9 5 0 - 1 9 7 0}$ & Após $\mathbf{1 9 7 0}$ \\
\hline $1.200 .000 \mathrm{~m}^{3} /$ ano & $530.000 \mathrm{~m}^{3} /$ ano & $350.000 \mathrm{~m}^{3} / \mathrm{ano}$ \\
\hline
\end{tabular}

(QUINTELA et al., 1982)

O decréscimo das cheias, nos anos após o «boom» da construção das barragens, parecia confirmar que o maior rio peninsular estaria controlado. No entanto, o estado de euforia desapareceu com as cheias catastróficas em 1978 e 1979, cujos picos de cheia foram acentuados pelas descargas contínuas das barragens, nem sempre coordenadas entre as autoridades espanholas e portuguesas. Esta situação levou à ruptura de vários diques de protecção, que deveriam proteger os campos e a população das cheias. Se é certo que as barragens diminuíram a frequência das cheias, sobretudo das cheias outonais, já nas situações anormalmente chuvosas de Inverno, contribuíram, por vezes, para o aumento dos caudais de ponta.

Quando o período de cheia termina, a planície aluvial permanece submersa devido à sua baixa altitude e inclinação. Durante as cheias de 1979 a área inundada atingiu $871 \mathrm{~km}^{2}$. Neste período, que durou 100 dias em 1979, um milhão de toneladas de sedimentos foram arrastados para o estuário do Tejo, o equivalente a $85 \%$ do total anual (VALE, 1981).

Actualmente, o Tejo continua um rio muito irregular. Nos anos $80,58 \%$ dos anos continuaram a registar cheias, $62 \%$ das quais em Fevereiro (88\% entre Dezembro e Fevereiro, Fig.6).

Quando o Tejo invade a sua planície aluvial, centenas de quilómetros quadrados de terrenos agrícolas ficam inundados, interrompendo estradas e isolando povoações. As populações locais encaram as cheias como um fenómeno normal. A confirmar este facto estão as diversas adaptações morfológicas e funcionais que apresentam as habitações sujeitas às cheias. Aliás, estas são mesmo consideradas benéficas, devido aos "nateiros» (siltes e argilas), que fertilizam os terrenos de cultura. 


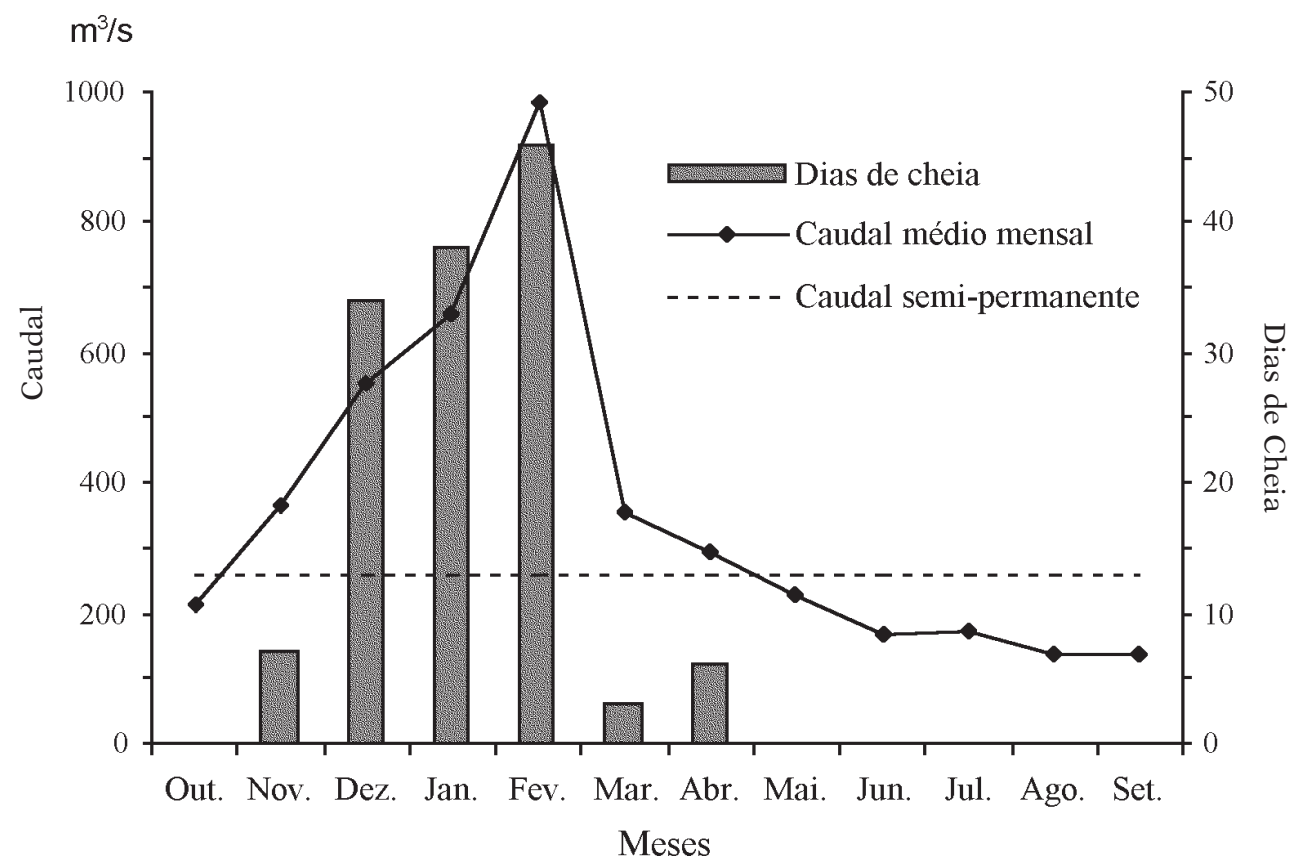

FIG. 6 - O rio Tejo em Ómnias-Santarém (1978/79 - 1989/90)

FIG. 6 - Tagus river at Ómnias-Santarém (1978/79 - 1989/90)

(Fonte/Source: Instituto da Água)

\section{AS CHEIAS NAS PEQUENAS BACIAS HIDROGRÁFICAS DO SUL: O EXEMPLO DA RIBEIRA DE COBRES}

A ribeira de Cobres, aqui utilizada como exemplo do comportamento dos cursos de água do Sul de Portugal, está localizada no Alentejo interior e é um dos afluentes da margem direita do rio Guadiana (Fig.1b). A bacia de drenagem definida pela estação hidrométrica de Monte da Ponte $\left(706 \mathrm{~km}^{2}\right.$ de área de drenagem) tem uma forma alongada, atinge $46 \mathrm{~km}$ de comprimento e possui altitudes quase sempre abaixo dos 300 metros, com excepção da área mais elevada, no sector montante da bacia. A variação altimétrica não excede, assim, 300 metros, indicando que os desníveis são muito fracos no interior da bacia. A forma e as características do relevo da bacia actuam, deste modo, como factores de atenuação dos caudais máximos nos cursos de água principais. No entanto, a ocupação do solo resume-se quase exclusivamente à presença do montado de azinho, predominante no sector montante, e a extensas áreas de culturas cerealíferas de sequeiro, largamente maioritárias na metade jusante da bacia de drenagem. A fraca protecção do solo daí decorrente traduz-se na consequente produção de sedimentos, a qual só não é maior devido aos fracos 
declives da bacia. Esta situação é agravada pela permeabilidade muito reduzida dos terrenos, onde predominam os xistos e os solos essencialmente argilosos, os quais favorecem o aumento da escorrência superficial. A fraca densidade florestal e a reduzida taxa de infiltração tornam os escoamentos da bacia extremamente dependentes dos quantitativos e intensidade da precipitação.

As ribeiras do Sul de Portugal Continental, de que a ribeira de Cobres é exemplo, apresentam o escoamento mais elevado durante o mês de Dezembro (o coeficiente mensal do caudal é superior a 3), coincidindo com o máximo absoluto da precipitação. A partir de Maio ou Junho, o caudal reduz-se drasticamente, tornando-se frequentemente nulo (Fig. 7). Esta situação prolonga-se até ao mês de Setembro e, frequentemente, até Outubro, durante as estiagens mais prolongadas, que se podem estender por 5 ou 6 meses. As primeiras chuvas outonais, quer ocorram durante Setembro ou Outubro, vão alimentar o solo ressequido durante o Verão, e não se traduzem normalmente em escoamento fluvial. No entanto, o regime dos cursos de água de Portugal, e em especial da região Sul, não se caracteriza apenas pelos enormes contrastes sazonais, mas também pela sua enorme irregularidade interanual, tanto no que diz respeito ao valores médios anuais como aos valores médios mensais. Na série considerada para a ribeira de Cobres (1958/59 a 1989/90) o coeficiente de flutuação (Qmax/ Qmin) foi de 632, o que mostra bem a variação dos caudais de ano para ano (Fig.8). O mesmo acontece quando se compara o mesmo mês para os vários

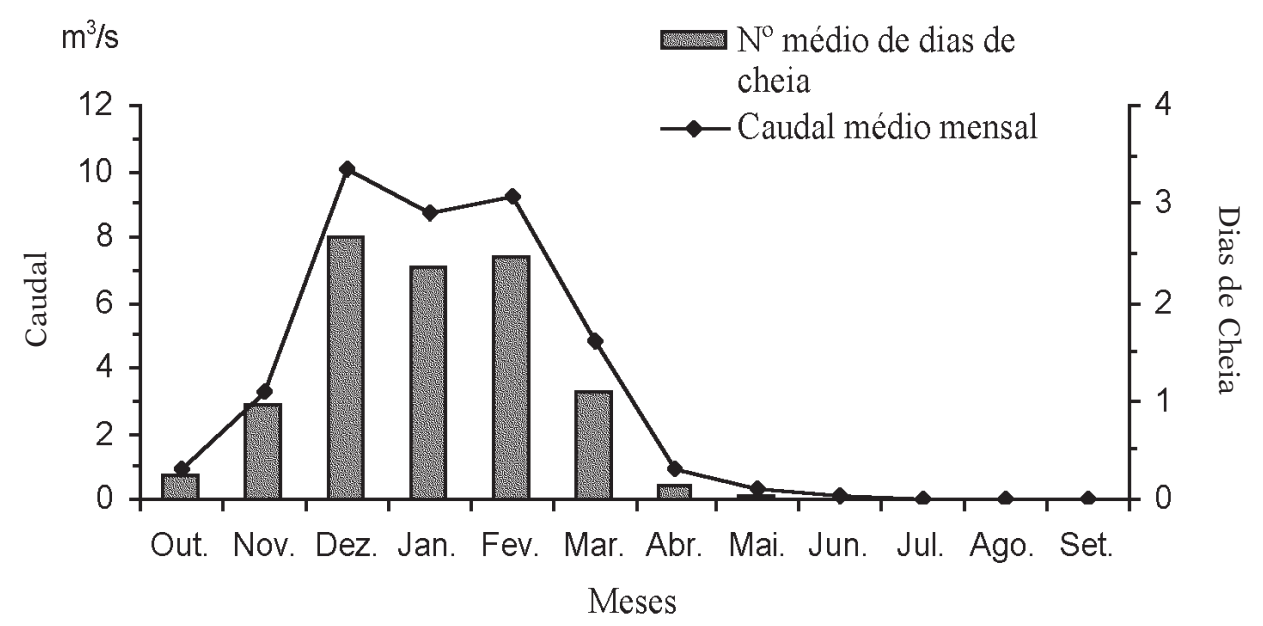

Fig. 7 - Caudal médio mensal e número médio de dias de cheia na ribeira de Cobres em Monte da Ponte (1958/59 - 1989/90)

FIG. 7 - Monthly mean discharge and average number of flood days of Cobres stream at Monte da Ponte (1958/59 - 1989/90)

(Fonte/Source: Instituto da Água) 


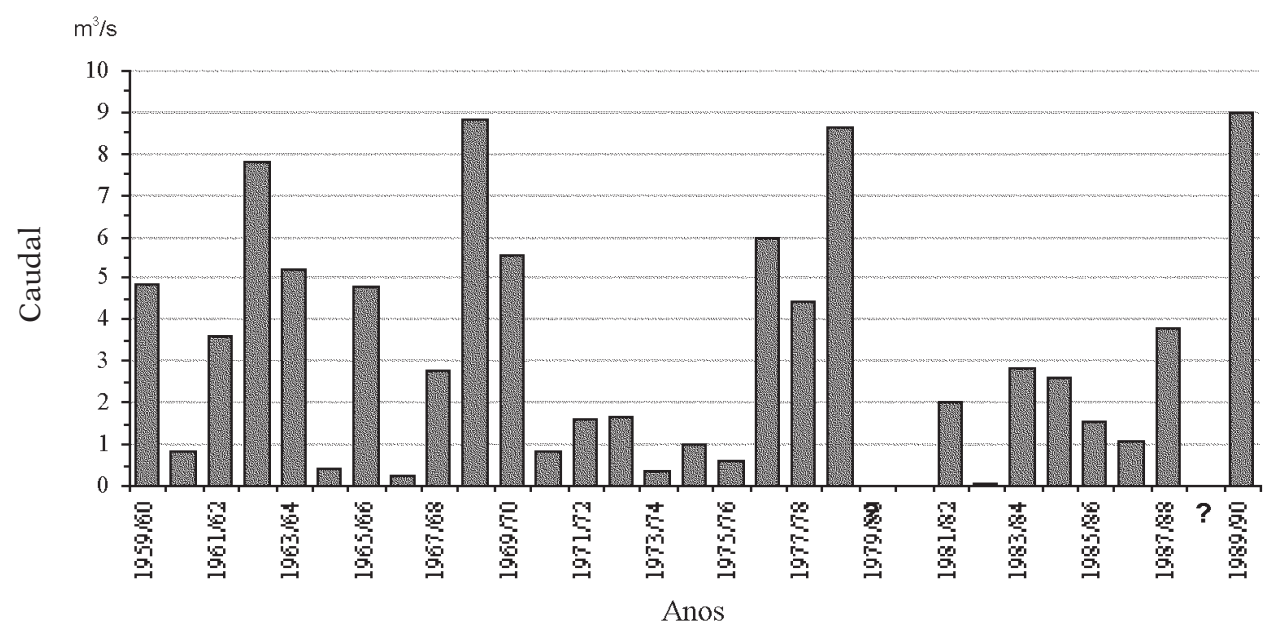

FIG. 8 - Caudal médio anual em Monte da Ponte (1958/59 - 1989/90)

FIG. 8 - Annual mean discharge at Monte da Ponte (1958/59 to 1989/90)

(Fonte/Source: Instituto da Água)

anos da série, particularmente entre Outubro e Maio. No mês mais húmido (Dezembro) o caudal médio mensal variou entre 0,02 no ano 1980/81 e 60,42 $\mathrm{m}^{3} / \mathrm{s}$ em 1989/90. Pelo contrário, o período de estiagem, de Junho a Setembro, apresenta variações muito reduzidas, em que o caudal é nulo ou muito próximo deste valor. Esta situação mostra que um maior escoamento anual se deve essencialmente a um aumento do caudal durante os meses mais húmidos e muito raramente devido à atenuação da estação seca. O período de estiagem é sempre bem marcado quer nos anos secos quer nos húmidos.

A definição de cheia baseou-se no valor obtido para o $9 .^{\circ}$ decil do mês de maior caudal (Dezembro) na série considerada (32 anos, de 1958/59 a 1989/90), ou seja, para a ribeira de Cobres $28,95 \mathrm{~m}^{3} / \mathrm{s}$. Este valor corresponde a cerca de 9 vezes o caudal médio anual, o que está de acordo com a ordem de grandeza obtida para algumas ribeiras do sul de Portugal. Para o período em questão foram registadas 149 situações de cheia, distribuídas por 317 dias entre Outubro e Maio, o que corresponde a cerca de 5 cheias/ano, com a duração de 10 dias/ano. No entanto, cerca de 70\% destas cheias ocorreram apenas durante os meses de Dezembro, Janeiro e Fevereiro, a que correspondem $76 \%$ do número de dias de cheia. As ocorrências em Outubro, Abril e Maio são pouco significativas (Fig.7).

A classificação dos valores mais elevados para os caudais médios diários fornece-nos uma informação complementar da intensidade do caudal e da sua distribuição ao longo dos meses mais húmidos (Fig.9). Assim, do universo de cheias definido, verifica-se que em 78 casos (52,3\% das ocorrências) foi ultrapassado o valor de $100 \mathrm{~m}^{3} / \mathrm{s}$, o que corresponde a 31,3 vezes o caudal médio 


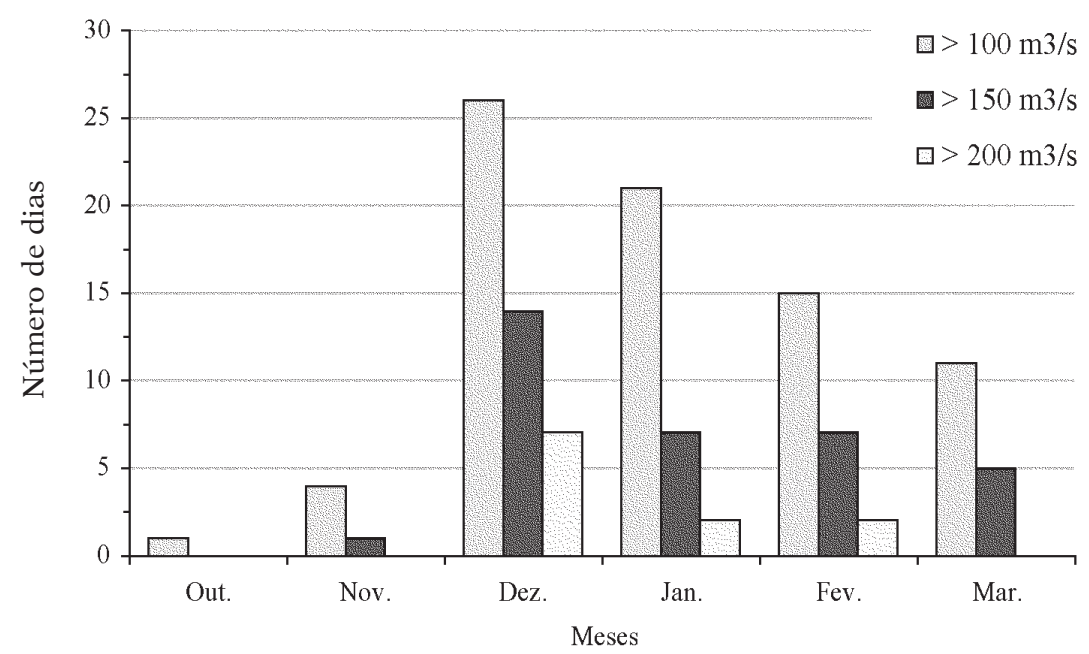

FIG. 9 - Caudal médio diário acima de $100 \mathrm{~m}^{3} / \mathrm{s}$ na ribeira de Cobres em Monte da Ponte (1958/59- 89/90)

FIG. 9 - Daily mean flood discharge over $100 \mathrm{~m}^{3} / \mathrm{s}$ in the Cobres stream at Monte da Ponte (1958/59-89/90)

(Fonte/Source: Instituto da Água)

diário, distribuídos entre Outubro e Março. Em Abril e Maio, não se verificam ocorrências acima daquele limite. Pelo contrário, cerca de 33\% dessas ocorrências concentram-se no mês de Dezembro, seguindo-se Janeiro com cerca de $27 \%$. Por sua vez, os caudais médios diários superiores a $150 \mathrm{~m}^{3} / \mathrm{s}$ (cerca de 49 vezes o caudal médio diário) ocorrem em 34 situações ( $22,8 \%$ das ocorrências), concentrando-se essencialmente durante o mês de Dezembro (cerca de 41\%). Os caudais mais elevados, com valores superiores a $200 \mathrm{~m}^{3} / \mathrm{s}(62,5$ vezes o caudal médio anual) ocorrem apenas durante os meses de Dezembro, Janeiro e Fevereiro, sendo a sua concentração largamente predominante no primeiro deste meses (cerca de 64\% das ocorrências). Deste modo, verifica-se que, quanto maiores são os valores considerados, maior é a sua concentração durante o mês de Dezembro (Fig. 9). A confirmar esta tendência, constata-se que o caudal máximo instantâneo, registado na série de dados, ocorreu em Dezembro: 600,42 $\mathrm{m}^{3} / \mathrm{s}$ (cerca de 188 vezes o caudal médio anual). O mês de Janeiro apresenta também valores máximos instantâneos elevados, acima dos $500 \mathrm{~m}^{3} / \mathrm{s}$. Nestes dois meses ocorreram cerca de $42 \%$ dos máximos instantâneos observados entre $1958 / 59$ e 1989/90.

Uma das características peculiares das cheias ocorridas neste tipo de bacias relaciona-se com a grande importância das cheias rápidas e sua influência nas actividades humanas ribeirinhas. De facto, são frequentes as subidas repentinas do caudal, resultantes da rápida resposta das ribeiras às chuvas intensas e 
concentradas, bastante vulgares no Sul de Portugal. Assim, verifica-se que 38\% das cheias ocorridas na ribeira de Cobres são rápidas, sendo um factor muito importante a ter em conta no correcto ordenamento do território e planeamento das actividades humanas. A maioria das cheias rápidas (cerca de 73\%) ocorrem entre Novembro e Fevereiro, embora o mês de Março possa também ser importante neste tipo de ocorrências (Fig.10). No entanto, ao contrário do verificado anteriormente, é no mês de Janeiro que a probabilidade de ocorrência de cheias rápidas é maior, seguindo-se Fevereiro e Dezembro. Tal situação dever-se-á aos valores elevados de precipitação, mas também à saturação do solo em água naquele mês e à existência de um volume de escoamento acumulado dos meses anteriores.

Interessante é, também, observar as tendências de variação destes fenómenos extremos ao longo das últimas décadas. De facto, verifica-se uma clara intensificação da importância das cheias durante os meses outonais, particularmente na década de 80 , em contraste com uma diminuição acentuada nos meses de Inverno e da Primavera (Fig.11). Igual tendência pode ser verificada para as cheias rápidas. Estas modificações seguem de perto a variação do comportamento da distribuição temporal dos quantitativos de precipitação registados nas últimas décadas para a área mediterrânea e previstos com base em alguns modelos climáticos baseados num cenário de duplicação do $\mathrm{CO}^{2}$ (PARRY et al, 1988; Rowntree, 1991 in CunHa, 1994).

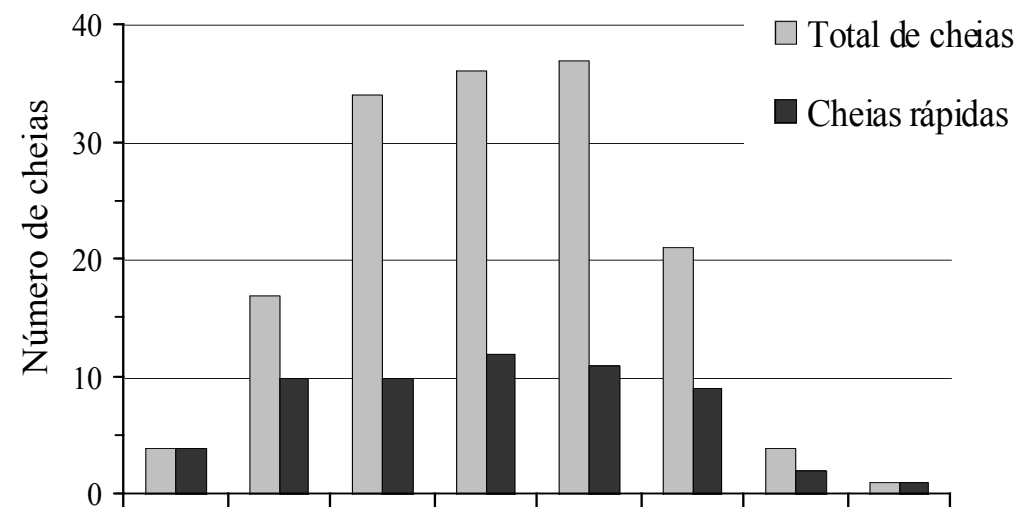

Out. Nov. Dez. Jan. Fev. Mar. Abr. Mai.

Meses

FIG. 10 - Número de cheias e de cheias rápidas na ribeira de Cobres em Monte da Ponte (1958/59-1989/90)

FIG. 10 -Number of floods and flash floods in the Cobres stream at Monte da Ponte (1958/59-1989/90)

(Fonte/Source: Instituto da Água) 


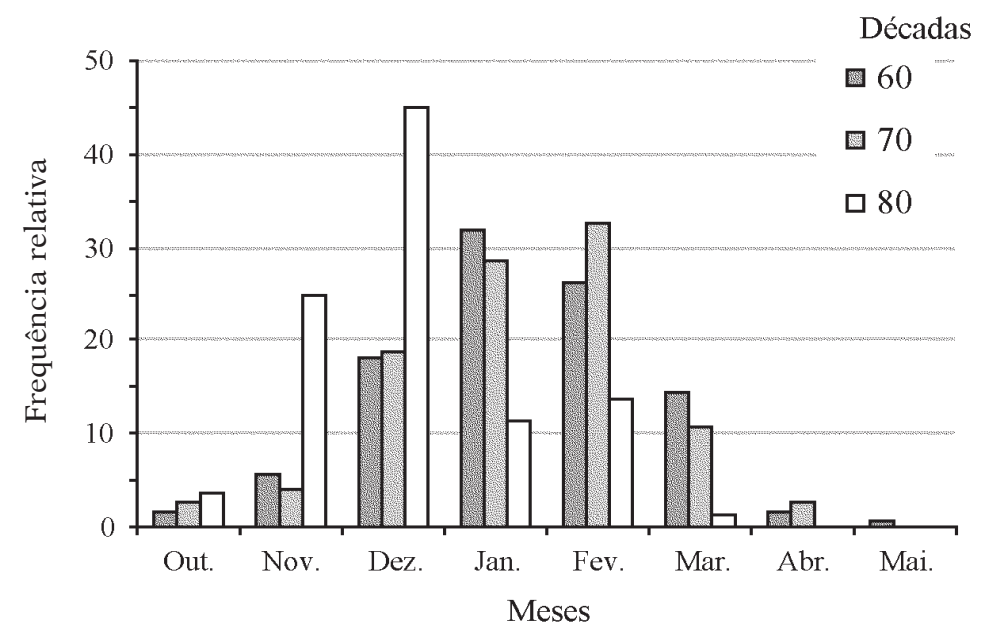

FIG. 11 - Frequência relativa mensal de cheias nos anos 60, 70 e 80 na ribeira de Cobre em Monte da Ponte

FIG. 11 - Monthly relative frequency of floods in the 60's, 70's and 80's of Cobres stream at Monte da Ponte

(Fonte/Source: Instituto da Água)

\section{AS CHEIAS RÁPIDAS DE 1967, 1983 E 1997}

As cheias rápidas são especialmente problemáticas em pequenas bacias-vertente, com tempos de concentração reduzidos, e sujeitas a uma urbanização caótica.

As cheias rápidas mais devastadoras ocorreram sempre em Novembro: em 1967, na região de Lisboa-Loures, em 1983, na região de Lisboa-Cascais e em 1997, no Alentejo e Algarve.

\section{As cheias rápidas de 1967 e de 1983 na região de Lisboa}

A cheia rápida de 1967 ocorreu na madrugada de 26 de Novembro na região de Lisboa (área de Loures). Foi devida a precipitações provocadas por uma depressão convectiva, resultante da interacção das circulações polar e tropical. A depressão começou por se formar, na região da Madeira, devido a uma invasão de ar frio em altitude (gota de ar frio), mantendo-se estacionária desde o dia 17. Mas, para esta área depressionária convergiram, simultaneamente, uma frente fria muito activa vinda de NW desde a região dos Açores e uma advecção de ar quente, vinda de SW, dirigida pelo jet subtropical (FERREIRA, 1985). Esta convergência provocou o enorme desenvolvimento de cumulo-nimbos e a deslocação da depressão de SW para NE, em direcção a Lisboa. A precipitação, muito elevada, caiu num curto intervalo de tempo. Na estação 
meteorológica de Monte Estoril (a oeste de Lisboa) das 10h do dia 25 às $10 \mathrm{~h}$ do dia 26 foram registados $159 \mathrm{~mm}$ (cerca de 1/5 da precipitação média anual), dos quais $129 \mathrm{~mm}$ em apenas cinco horas (das 19h do dia 25 às 0h do dia 26) e $60 \mathrm{~mm}$, entre as $21 \mathrm{e}$ as $22 \mathrm{~h}$. O período de retorno foi calculado em 500 anos (Costa, 1986).

A cheia rápida provocada por esta chuvadas durou cerca de 12h (AMARAL, 1968), mas infelizmente, por falta de registos (inexistência de estações hidrométricas ou destruição destas pela cheia), não existem dados sobre os caudais atingidos. A cheia foi especialmente catastrófica, por ter ocorrido na periferia de Lisboa, numa área de grande densidade populacional. Morreram cerca de 700 pessoas, a maioria das quais vivia em habitações clandestinas implantadas nos leitos de cheia. No entanto, também caíram alguns prédios de apartamentos, por efeito do sapamento lateral das ribeiras, que tinham sido construídos, com licença de construção, na margem do leito menor das ribeiras! No fim da cheia a espessura da lama depositada chegou a encher os andares térreos de muitas casas e a cobrir automóveis (AMARAL, 1968).

A cheia rápida de 1983 ocorreu a 18 de Novembro. Neste dia, uma depressão muito cavada (985 hPa), localizada a SW dos Açores (cuja instabilidade foi reforçada por uma invasão de ar frio em altitude no dia 17, levando-a a evoluir em gota fria), avançou em direcção à Península Ibérica.

A partir das $20 \mathrm{~h}$ do dia 18 , registou-se um período de chuvas intensas, que se prolongaram até à tarde do dia 19 . O período de retorno dessas precipitações foi estimado entre 100 e 200 anos (COSTA, 1986). A cheia abrangeu uma área menos extensa do que a de 1967, sendo o número de mortos muito menor (10).

Particularmente atingida foi a baixa de Cascais, construída sobre o leito da ribeira das Vinhas, a qual se encontra aí canalizada subterraneamente. Esta ribeira tem uma bacia-vertente de cerca de $30 \mathrm{~km}^{2}$, a qual recebeu, em $12 \mathrm{~h}, 140$ $\mathrm{mm}$. Estimou-se assim uma contribuição específica da bacia em cerca de 6 $\mathrm{m}^{3} / \mathrm{s} / \mathrm{km}^{2}$, a que corresponde um caudal de ponta de $180 \mathrm{~m}^{3} / \mathrm{s}$ (Quintela e CoutinHo, 1983). A água subiu vários metros na baixa de Cascais, atingindo a cota máxima em apenas meia-hora (Coutinho, 1984), rebentando com o paredão da praia da Ribeira, onde vai desaguar a ribeira das Vinhas.

\section{As cheias rápidas de 1997 no Alentejo e Algarve}

Os meses de Outubro e Novembro de 1997 foram particularmente difíceis para Portugal, pois sucederam-se cheias rápidas e movimentos de terreno em várias regiões do sul do Continente e nas ilhas dos Açores e da Madeira. Ao todo morreram 40 pessoas, 29 das quais nos Açores, a 31 de Outubro, quando um deslizamento soterrou parte da povoação de Ribeira Quente, entre as $4 \mathrm{~h}$ e as $5 \mathrm{~h}$ da madrugada.

Apenas 6 dias antes, em 26 de Outubro, um autêntico dilúvio abateu-se sobre a Serra de Monchique (Algarve), onde a grande inclinação dos cursos de água originou uma rápida propagação da onda de cheia. As enxurradas trans- 


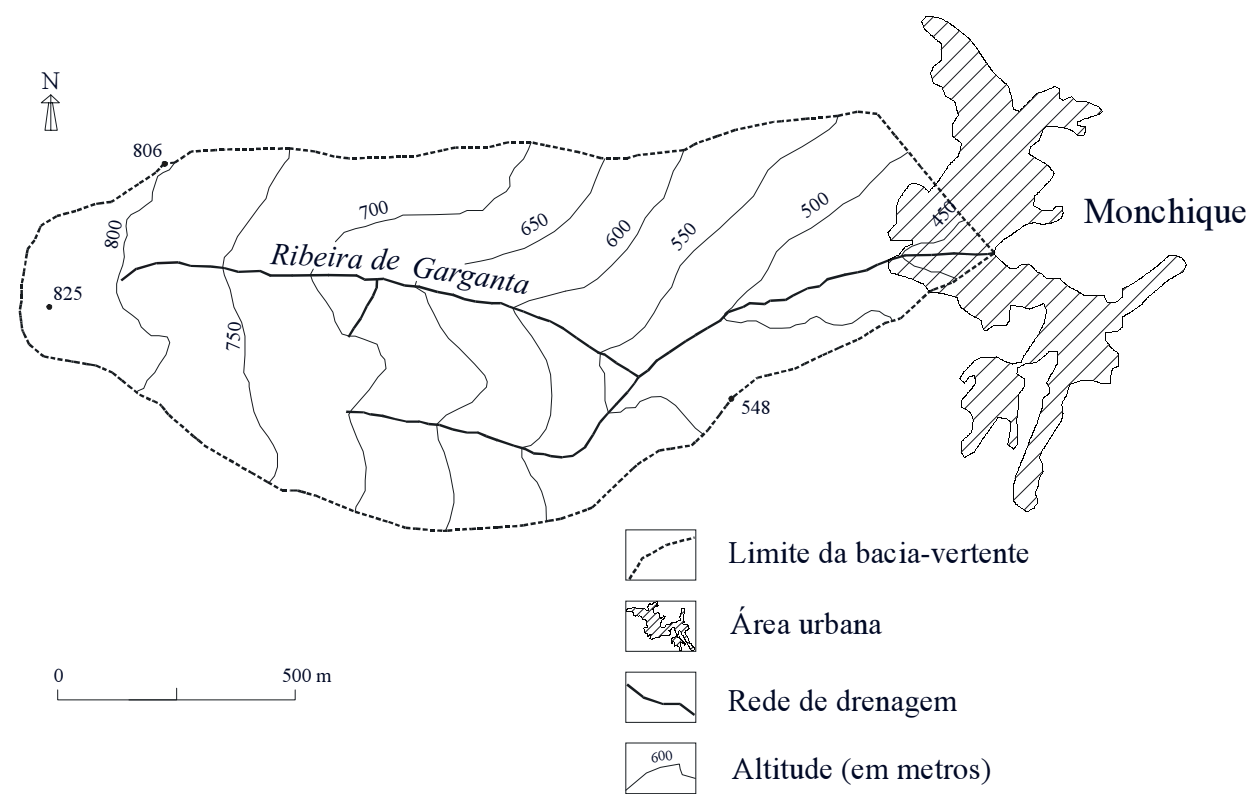

FIG. 12 - A bacia-vertente da ribeira de Garganta a montante de Monchique FIG. 12 - The Garganta catchment upstream Monchique village

portaram várias toneladas de blocos de sienito das mais variadas dimensões, areia e lama, bem como troncos de árvores, destruindo pontes, estradas e galgando povoações.

A ribeira da Garganta possui uma bacia-vertente diminuta $\left(1,1 \mathrm{~km}^{2}\right)$, mas tem uma inclinação média do canal de $18 \%$, descendo $360 \mathrm{~m}$ em apenas $1965 \mathrm{~m}$ de comprimento (Fig. 12). A litologia da bacia é constituída por sienitos meteorizados e a ocupação do solo é dominada por matas de eucaliptos e Quercus.

A precipitação registada em Monchique entre as 0 e as 6 horas da madrugada do dia 26 atingiu $274 \mathrm{~mm}$ (Fig. 13), o que constitui o dobro da precipitação média do mês $(138 \mathrm{~mm})$ e $1 / 5$ da precipitação média anual, correspondendo a um período de retorno de 1000 anos (RodRigues, Brandão, Álvares, 1998)! A intensidade da precipitação atingiu $164 \mathrm{~mm} / \mathrm{h}$, entre as 3 e as 3.05 horas. A ribeira da Garganta, com um tempo de concentração de 35 minutos drenou durante cerca de 7 horas, $319000 \mathrm{~m}^{3}$, com um caudal específico de $11 \mathrm{~m} / 3 / \mathrm{s} / \mathrm{km}^{2}$.

Mais uma vez, a acção humana contribuiu para o agravamento dos prejuízos causados pelas cheias. Parte da vila de Monchique assenta sobre a ribeira da Garganta (Fig.12), que foi coberta e canalizada. As casas foram implantadas transversalmente ao vale. Estas casas serviram de barreira ao livre escoamento das águas, da lama e dos blocos. Como consequência, a ribeira rebentou com parte do colector por onde corria, galgou as ruas levantando a 


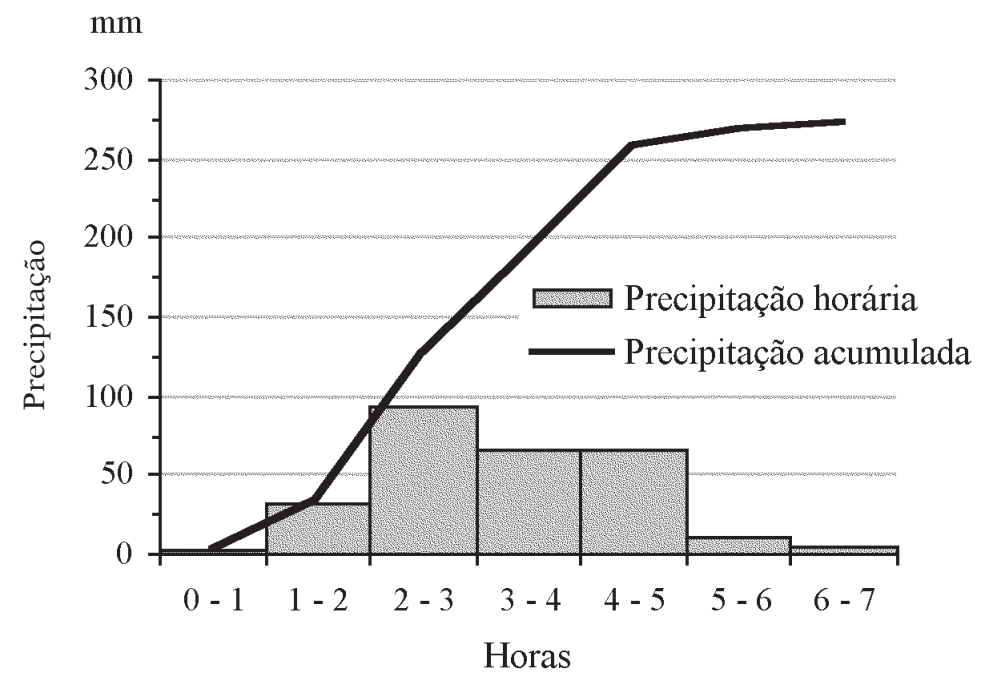

FIg. 13 - Precipitação horária em Monchique entre as 0 e as 7 horas de 26 de Outubro de 1997

FIG. 13 - Hourly rainfall in Monchique between 0 and 7 a.m. of $26^{\text {th }}$ October 1997

(Fonte/Source: Instituto Meteorológico)

calçada e entrou pelas casas submergindo os pisos térreos com blocos e lama. Mais a jusante, em Caldas de Monchique verificou-se situação idêntica: a ribeira foi coberta e canalizada, e as casas (entre elas o hotel das Caldas de Monchique e a empresa Águas de Monchique) foram construídas transversalmente ao vale.

Quinze dias mais tarde, em 5 de Novembro, uma depressão vinda duma latitude tropical (menos de $30^{\circ} \mathrm{N}$ ), deslocou-se do Atlântico para o SW da Península Ibérica. Desde o dia 3 de Novembro que a depressão era continuamente alimentada por ar frio em altitude (gota fria). $O$ gradiente térmico vertical que se estabeleceu no interior do vortex ciclónico acentuou a ascendência do ar húmido e quente da baixa troposfera. Durante as últimas horas de 5 de Novembro, o Alentejo foi varrido por uma tempestade caracterizada por períodos de chuva muito intensa, ventos fortes e trovoadas. Esta tempestade cruzou o sul do País (felizmente em áreas de baixa densidade populacional), arrasando uma faixa de SW para NE, desde Aljezur até Elvas e dirigiu-se para Espanha. Em Beja a precipitação alcançada em 24 horas foi 1/5 da precipitação média anual, ou seja, $104 \mathrm{~mm}$. Destes, $80 \mathrm{~mm}$ ocorreram nas últimas 6 horas do dia 5 de Novembro. Entre as $20 \mathrm{~h} 50 \mathrm{~m}$ e as $21 \mathrm{~h} 10 \mathrm{~m}$, ou seja, em apenas 20 minutos, caíram $29 \mathrm{~mm}$.

A cheia que se lhe seguiu destruiu pontes centenárias e fez 11 mortos em Portugal e 21 na área de Badajoz (Espanha). As ribeiras das pequenas bacias de drenagem, praticamente sem vegetação e com um substrato xistoso impermeável, responderam com enorme rapidez, ainda no final do dia 5, inundando 
casas implantadas no leito de cheia das ribeiras. Os seus habitantes, mais habituados à escassez de água (devido às secas frequentes que afectam esta região do País) do que ao seu excesso, foram apanhados de surpresa, morrendo as vítimas afogadas dentro das suas próprias casas ou arrastadas pela corrente.

O facto de o Oceano Atlântico estar mais quente do que o habitual nesta época do ano e de muitas das depressões que originaram estas chuvas intensas terem um trajecto oceânico entre 30 e $40^{\circ} \mathrm{N}$, sofrendo a interacção das circulações tropical e polar, pode ter contribuído para estas chuvas excepcionais. Contudo, as suas consequências foram ampliadas pela falta de ordenamento do território, pela não observância das regras mais elementares de planeamento hidráulico e pelo não cumprimento da lei, mesmo por parte das entidades oficiais.

\section{CONCLUSÃO}

A grande irregularidade dos rios portugueses dificulta o planeamento e gestão dos recursos hídricos, nomeadamente no Sul do país, onde são frequentes as secas, por vezes interrompidas por cheias brutais.

Nas grandes bacias hidrográficas, como a do rio Tejo, o sistema de barragens reduz a frequência das cheias, especialmente as de Outono, visto que, após o período seco de Verão, as barragens possuem uma maior capacidade de encaixe do escoamento. Conjuntamente com a redução da frequência de cheias verifica-se o decréscimo da deposição de sedimentos (siltes e argilas), que fertilizam a planície aluvial do rio Tejo, e também uma acentuada erosão das praias localizadas a sul do estuário do Tejo, que são alimentadas principalmente a partir das aluviões arenosas.

Pelo contrário, nas pequenas bacias de drenagem com um regime natural (sem influência das barragens) existe uma clara intensificação da importância das cheias durante os meses de Outono, durante as últimas décadas, em contraste com uma acentuada diminuição nos meses de Inverno e Primavera. Estas modificações seguem de perto a variação de comportamento da distribuição temporal dos quantitativos de precipitação registados nas últimas décadas para a área mediterrânea.

Esta tendência não deixa de ser preocupante: por um lado, a concentração de precipitação, num menor número de meses, diminui a disponibilidade de água nos restantes e exige uma maior necessidade de armazenamento; por outro lado, esta concentração traduz-se na maior intensidade da precipitação no período outonal, com o consequente agravamento do número e intensidade das cheias e aumento da perda de solo.

Se é verdade que a intensidade e concentração das chuvas são a causa próxima das cheias rápidas, também é verdade que os prejuízos e vítimas mortais resultantes se devem a uma acção humana irresponsável. A urbanização descontrolada, a partir dos anos 60, da área envolvente da cidade de 
Lisboa, devido à migração de milhares de pessoas do interior do país em direcção à capital, permaneceu, sem que se tivesse tirado qualquer ensinamento dos acontecimentos de Novembro de 1967. A destruição da vegetação nas áreas de maiores declives, com o consequente aumento da capacidade erosiva das águas de escorrência, a impermeabilização generalizada dos terrenos, a insuficiência ou inadequação dos colectores pluviais (a que se juntam, muitas vezes, as descargas dos esgotos), a criação de estrangulamentos artificiais que constituem obstáculos ao escoamento (canalização coberta de troços das ribeiras, muros e aterros transversais às linhas de água, construção nos leitos de cheia ou nas margens dos leitos menores, entulhamento dos leitos das ribeiras), foram as causas que contribuíram para o agravamento deste tipo de cheias. O carácter efémero dos pequenos cursos de água, que podem permanecer secos por vários anos, cria uma falta de percepção do risco de cheia pela população e, em muitos casos, pelas entidades oficiais.

Mas também numa região pouco povoada, como é o Alentejo, a acção humana é um factor agravante das cheias. A construção nos leitos de cheia e implantação das casas transversalmente aos fundos de vale, servem de barreira ao livre escoamento das águas, contribuindo para agravar o efeito das cheias.

O desordenamento do território constitui assim a principal causa das mortes causadas pelas cheias. A grande maioria das vítimas foram encurraladas nas suas próprias casas, construídas nos leitos de cheia, muitas vezes ilegalmente, e outras com a permissão das entidades municipais.

\section{BIBLIOGRAFIA}

Alexandre, L. M.; Borralho, M. E. (1982) - Defesa contra as cheias na Lezíria Grande de Vila Franca de Xira, Simpósio sobre a Bacia Hidrográfica Portuguesa do Tejo, vol. 1, A.P.R.H., Lisboa, 19 p.

Amaral, I. (1968) - As inundações de 25/26 de Novembro de 1967 na Região de Lisboa, Finisterra-Revista Portuguesa de Geografia, Lisboa, III(5), CEG: 79-84.

Costa, P. C. (1986) - As cheias rápidas de 1967 e 1983 na Região de Lisboa, in Estudos em homenagem a Mariano Feio, Lisboa: 601-616.

Coutinho, M. (1984) - Intervenção na bacia e na rede hidrográfica. Seminário sobre as cheias de Novembro de 1983, Sec. Est. Ob. Públic., Lisboa: 3.1-3.22.

Cunha, L. V. (1994) - Recursos Hídricos da Europa, In O Jardim Comum Europeu, Quetzal ed. / F.L.A.D., Lisboa: 279-351.

Daveau, S. (1987) - Geografia de Portugal. II. O ritmo climático e a paisagem, Ed. João Sá da Costa, Lisboa: 487-535.

Daveau, S. (1995) - Portugal Geográfico, Lisboa, Ed. João Sá da Costa: 58-71.

D.G.R.A.H. (1979) - Regularização do Rio Tejo. Plano Geral-volume síntese, Direcção-Geral dos Recursos e Aproveitamentos Hidráulicos, Hidrotécnica Portuguesa, Lisboa. 
Ferreira, D. B. (1985) - Les dépressions convectives du bassin atlantique nord subtropical oriental, Finisterra Finisterra -Revista Portuguesa de Geografia, Lisboa, XX(39) : 25-45.

Loureiro, J. J. M.; MAcedo, M. E. (1986) - Bacia Hidrográfica do Rio Tejo, in Monografias Hidrológicas dos Principais Cursos de Água de Portugal continental, Lisboa, D.G.R.A.H.: 281-335.

PARRY, M. et al (1988) - The Impact of Climatic Variations on Agriculture vol.1, in Assessment in Cool, Temperate and Cold Regions, Dordecht, Kluwer Publishers.

Quintela, A. et al. (1982) - Avaliação do transporte sólido do Rio Tejo e a sua influência no leito. In Simpósio sobre a Bacia Hidrográfica Portuguesa do Tejo, vol.1, A.P.R.H., Lisboa, $20 \mathrm{p}$.

Quintela, A.; Coutinho, M. (1983) - Inundação de Novembro de 1983 na região de Lisboa. Conferência no âmbito do Mestrado de Hidráulica e Recursos Hídricos.

Ramos, C. (1993) - As cheias de Dezembro de 1989 em pequenas bacias-vertente da margem direita do baixo Tejo, Estudos de Geografia Física e Ambiente, 32, LAGF, CEG, Lisboa:119-132.

Ramos, C. (1994) - Condições geomorfológicas e climáticas das cheias da Ribeira de Tera e do Rio Maior (Bacia Hidrográfica do Tejo). Dissertação de doutoramento, Departamento de Geografia, F.L. Universidade de Lisboa, Lisboa, 520 p.

Ramos, C. (1996a) - The natural regimes of portuguese rivers, in A.B. Ferreira e G.T. Vieira (eds), Fifth European Intensive Course on Applied Geomorphology-Mediterranean and Urban Areas, Erasmus, ICP-91/96-I-1226/07, publ. 9, Universidade de Lisboa:151-160.

Ramos, C. (1996b) - Hydrologic diversity in the Tagus'portuguese basin, in A.B. Ferreira e G.T. Vieira (eds), Fifth European Intensive Course on Applied GeomorphologyMediterranean and Urban Areas, Erasmus, ICP-91/96-I-1226/07, publ. 9, Universidade de Lisboa:161-170.

Ramos, C. (1996c) - The floods of the river Tagus, in A.B. Ferreira e G.T. Vieira (eds), Fifth European Intensive Course on Applied Geomorphology - Mediterranean and Urban Areas, Erasmus, ICP-91/96-I-1226/07, publ. 9, Universidade de Lisboa: 171-176.

Rodrigues, R.; Brandão, C.; Álvares, T. (1998) - Qual o grau de excepcionalidade das cheias ocorridas no início do ano hidrológico de 1997/98. Actas do 4. ${ }^{\circ}$ Congresso da Água, Lisboa, A.P.R.H.:43-44.

SEQUEIRA, M. N. (1986) - Avaliação dos prejuízos causados pelas cheias e análise custo-benefício da execução de obras destinadas a evitá-los: a lição da experiência do municipio de Cascais. II SILUSB, Lisboa, 15p.

Sobrinho, A. (1980) - Os temporais de Fevereiro de 1979 no Ribatejo e Região de Lisboa, Finisterra -Revista Portuguesa de Geografia, Lisboa XV(29), 85-93.

VALE, C. (1981) - Entrada de matéria em suspensão no estuário do Tejo durante as cheias de Fevereiro de 1979, Recursos Hidricos, 2 (1):37-45.

Ventura, J. E. (1987) - As gotas de ar frio e o regime da precipitação em Portugal, Finisterra -Revista Portuguesa de Geografia, Lisboa, XXII(43): 39-69. 